\title{
Comparison of SSM/I ice-concentration algorithms for the Weddell Sea
}

\author{
BARBARA A. BURNS \\ Institute of Remote Sensing, University of Bremen, 2800 Bremen 33, Germany
}

\begin{abstract}
Four different algorithms for retrieving ice concentration from passive microwave imagery are applied to SSM/I data collected over the Weddell Sea in September 1989. Comparison of the results along a typical transect from the ice edge to the coast shows point-wise differences of up to $45 \%$ in ice concentration. The observed differences can largely be explained by the different combinations of the 19 and $37 \mathrm{GHz}$, horizontal and vertical polarization, data channels utilized by each algorithm. Through their frequency/polarization signatures, and with the aid of coincident surface observations, the differences are further related to ice type, specifically the presence of grease ice or thin ice, and surface conditions.
\end{abstract}

\section{INTRODUCTION}

The importance of sea-ice cover in global and regional climate is well recognized. For the purposes of climate modelling estimates of ice concentration (percentage ice cover per unit area) with accuracies of a few per cent are required. Satellite passive microwave imagers, with their large-area coverage and independence from cloud and illumination conditions, are well suited to provide this information. A number of algorithms have been developed to retrieve ice concentration from such data, each using somewhat different combinations of the frequency and polarization channels available, and each producing therefore somewhat different estimates. This paper presents a comparison study of ice-concentration estimates derived for the Weddell Sea using four of these algorithms. They are applied to data collected by the Special Sensor Microwave Imager (SSM/I) on single overpasses of the Weddell Sea in late September 1989. Coincident surface observations and high-resolution $(1 \mathrm{~km})$ Advanced Very High Resolution Radiometer (AVHRR) imagery obtained during the Winter Weddell Gyre Study (WWGS'89) are used to help interpret the differences in ice concentrations produced by the different algorithms.

\section{BRIEF DESCRIPTION OF ALGORITHMS}

The four algorithms for deriving ice concentration considered in this study are described only briefly here; complete descriptions can be found in the literature cited. All are based on a linearization of the radiative-transfer equation relating the observed brightness temperature to contributions from ice, ocean and atmosphere within the field of view. They generally assume that the atmospheric contribution is small and can be treated as a bias independent of ice concentration. All require the use of two or more of the four 19 and $37 \mathrm{GHz}$, horizontal and vertical polarization, radiometer channels. Only the estimation of total-ice concentration is examined in this paper; concentrations of ice-type fractions are not considered.

\section{COMISO algorithm}

The algorithm used by Comiso in many Antarctic sea-ice analyses is described in Comiso and Sullivan (1986). As applied here, the algorithm uses the 19 and $37 \mathrm{GHz}$ vertically polarized channels. The $19 \mathrm{GHz}$ channel provides the primary information on open-water contributions while the $37 \mathrm{GHz}$ channel is used to resolve the ambiguity between decreased ice concentration and decreased ice brightness temperature (emissivity) due to scattering within the ice or snow layer. Under this scheme, the total ice concentration $C$ is given by

$$
C=\left(\mathrm{TB}(19)-\mathrm{TB}_{\text {ow }}(19)\right) /\left(\mathrm{TB}_{\mathrm{i}}(19)-\mathrm{TB}_{\text {ow }}(19)\right)
$$

where $\mathrm{TB}(19)$ is the measured brightness temperature at $19 \mathrm{GHz}, \mathrm{TB}_{\text {ow }}$ is the brightness temperature tie point for open water, and $\mathrm{TB}_{\mathrm{i}}$ is the brightness temperature tie point for ice. $\mathrm{TB}_{\mathrm{i}}$ is not fixed but is derived from the measured values $\mathrm{TB}(19)$ and $\mathrm{TB}(37)$ using a linear model relating the 19 and $37 \mathrm{GHz}$ signatures of $100 \%$ ice. The algorithm also accounts for possible unrealistically highice concentrations over open water due to atmospheric disturbances; it can resolve ice concentrations no lower than $8 \%$ as a result.

\section{SFR algorithm}

The algorithm developed by Swift and others (1985) has 
been recommended for use with data from the European Space Agency's future Multi-frequency Imaging Microwave Radiometer (MIMR). Like the COMISO algorithm, it is also a frequency scheme using the 19 and $37 \mathrm{GHz}$ channels. It differs primarily in that the tie points are not set but derived directly from the data themselves. The original formulation also allows for explicit input of surface-temperature information. However, in their application the authors assume a mean surface temperature for ice and open water; in this case, the algorithm reduces exactly to that of Comiso. In its application here, the surface temperature $\left(\mathrm{T}_{\mathrm{s}}\right)$ dependence has been maintained with $\mathrm{T}_{s}$ (open water) assumed to be $-1.8^{\circ} \mathrm{C}$ and $T_{s}$ (sea ice) calculated from a relationship given by Comiso and others (1989) between air and snow-ice interface temperatures. Air temperatures have been taken from the meteorological record obtained during WWGS'89. The SFR algorithm takes no account of atmospheric disturbance over open water.

\section{NASA algorithm}

The NASA team algorithm first described by Cavalieri and others (1984) makes use of both frequency and polarization information at 19 and $37 \mathrm{GHz}$. Determination of ice concentration is based on the fact that at $19 \mathrm{GHz}$ the polarization of open water is much greater than that of ice. This is expressed through a polarization ratio $(\mathrm{PR})$ defined as

$$
\mathrm{PR}=(\mathrm{TB}(19 \mathrm{~V})-\mathrm{TB}(19 \mathrm{H})) /(\mathrm{TB}(19 \mathrm{~V})+\mathrm{TB}(19 \mathrm{H})) \text {. }
$$

As in the previous two algorithms, the relationship between 19 and $37 \mathrm{Ghz}$ is used to resolve variations in ice signatures from ice-concentration variations. To this end, a spectral gradient ratio (GR) is defined

$$
\mathrm{GR}=(\mathrm{TB}(37 \mathrm{~V})-\mathrm{TB}(19 \mathrm{~V})) /(\mathrm{TB}(37 \mathrm{~V})+\mathrm{TB}(19 \mathrm{~V}))
$$

The total-ice concentration is then given by

$$
\begin{aligned}
C= & (\mathrm{A} 0+\mathrm{A} 1 * \mathrm{PR}+\mathrm{A} 2 * \mathrm{GR}+\mathrm{A} 3 * \mathrm{PR} * \mathrm{GR}) / \\
& (\mathrm{B} 0+\mathrm{B} 1 * \mathrm{PR}+\mathrm{B} 2 * \mathrm{GR}+\mathrm{B} 3 * \mathrm{PR} * \mathrm{GR})
\end{aligned}
$$

where the As and Bs are functions of fixed tie points for ice and open water. To eliminate atmospheric effects over open water, a "weather filter" is applied (Gloersen and Cavalieri, 1986) which effectively means that ice concentrations less than $15 \%$ cannot be measured.

\section{NAVY algorithm}

The algorithm recommended by Atmospheric Environment Service, Canada, to the U.S. Navy (Hollinger, 1989) differs significantly from the other algorithms in that relationships between total-ice concentration and the measured brightness temperatures do not explicitly include ice and water tie points. This algorithm also makes extensive tests on the data from the four channels at 19 and $37 \mathrm{GHz}$ to determine when clouds and atmospheric effects (ocean roughness) affect brightness temperatures. Based on these tests, ice concentrations above a value of $15 \%$ are calculated with one of two equations:
Case I: clouds and ocean roughness NOT important

$$
C=(\mathrm{TB}(37 \mathrm{~V})+0.5 * \mathrm{~TB}(37 \mathrm{H})-(265) / 100 \text {, }
$$

Case II: clouds and ocean roughness ARE important

$$
C=C_{1} * \mathrm{~TB}(37 \mathrm{~V})+C_{2} * \mathrm{~TB}(19 \mathrm{~V})+C_{3}
$$

where the $C$ s are fixed sets of coefficients, one for summer and one for winter conditions. It should be noted that this algorithm has been developed for the Arctic and no adjustment has been made to the coefficients for Antarctic ice conditions. In contrast, both NASA and COMISO algorithms have distinct Arctic and Antarctic tie points. That the coefficients for this algorithm are fixed and include no ratios of measured brightness temperatures means a possible sensitivity to surface-temperature fluctuations.

\section{ICE-CONCENTRATION RESULTS AND COMPARISONS}

In this study, the algorithms have been applied to data from single SSM/I overpasses of the Weddell Sea to preserve the fidelity of the brightness-temperature measurements and to make use of temporally coincident surface-temperature data. The ice-concentration estimates are then re-gridded to a polar stereographic projection for examination of specific geographic areas.

Ice-concentration estimates have been derived for the period 24-30 September 1989 during which large parts of the Weddell Sea area were cloud-free. Figure 1 shows an AVHRR (visible channel) image of the area obtained on 30 September 1989. Cloud cover can be seen in the western Weddell Sea and over much of the ice edge. Algorithm results have been compared for the entire area

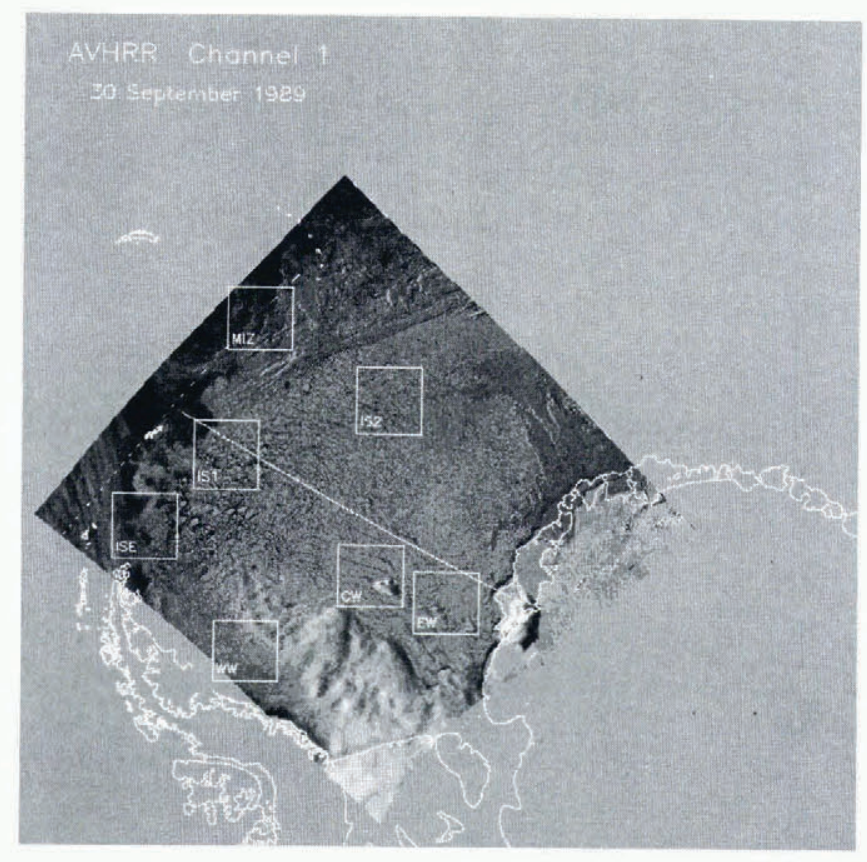

Fig. 1. AVHRR visible image (channel 1) of the Weddell Sea study area on 30 September 1989. Locations of subareas and the profile discussed in the text are shown. 


\begin{tabular}{lcccc}
\hline \multicolumn{1}{c}{ Area } & COMISO & SFR & NASA & NAVY \\
\hline MIZ & $61(64 \pm 3)$ & $53(58 \pm 3)$ & $54(56 \pm 2)$ & $64(65 \pm 5)$ \\
WW & $99(99 \pm 1)$ & $90(94 \pm 2)$ & $95(93 \pm 2)$ & $99(98 \pm 1)$ \\
EW & $95(97 \pm 1)$ & $85(89 \pm 2)$ & $95(97 \pm 1)$ & $89(92 \pm 3)$ \\
CW & $98(99 \pm 1)$ & $89(93 \pm 2)$ & $90(91 \pm 2)$ & $91(96 \pm 3)$ \\
ISE** & $80(48 \pm 4)$ & $73(51 \pm 4)$ & $75(46 \pm 4)$ & $73(54 \pm 4)$ \\
IS1 & $89(89 \pm 3)$ & $81(82 \pm 2)$ & $78(74 \pm 4)$ & $53(78 \pm 17)$ \\
IS2 & $100(100 \pm 0)$ & $91(94 \pm 1)$ & $82(81 \pm 2)$ & $92(94 \pm 4)$ \\
\hline
\end{tabular}

* $\mathrm{MIZ}=$ Marginal ice zone; $\mathrm{WW}=$ western Weddell Sea; $\mathrm{EW}=$ eastern Weddell Sea; $\mathrm{CW}=$ central Weddell Sea; ISE = Ice station at edge; IS1 = Ice station \#1; IS2 = Ice station \#2.

** Partial coverage of area on 30 September; not used in mean.

of the Weddell Sea covered in a single overpass as well as for specific areas of interest: the marginal ice zone, the western Weddell Sea (site of older ice), the eastern Weddell Sea (younger ice), the central Weddell Sea, and sites of ice stations during WWGS' 89 . The locations of these areas, each approximately $325 \mathrm{~km}^{2} \times 325 \mathrm{~km}^{2}$ in size, are shown in Figure 1.

Table 1 presents the ice concentration estimates for these areas from a single overpass on 30 September. Weekly means and standard deviations for the same overpass (i.e. same time of day and satellite orbit configuration) are given in parentheses. The results indicate that the COMISO algorithm consistently gives the highest (or equally high) estimates in these areas. The NASA algorithm estimates, on the other hand, are consistently among the two lowest for all areas except
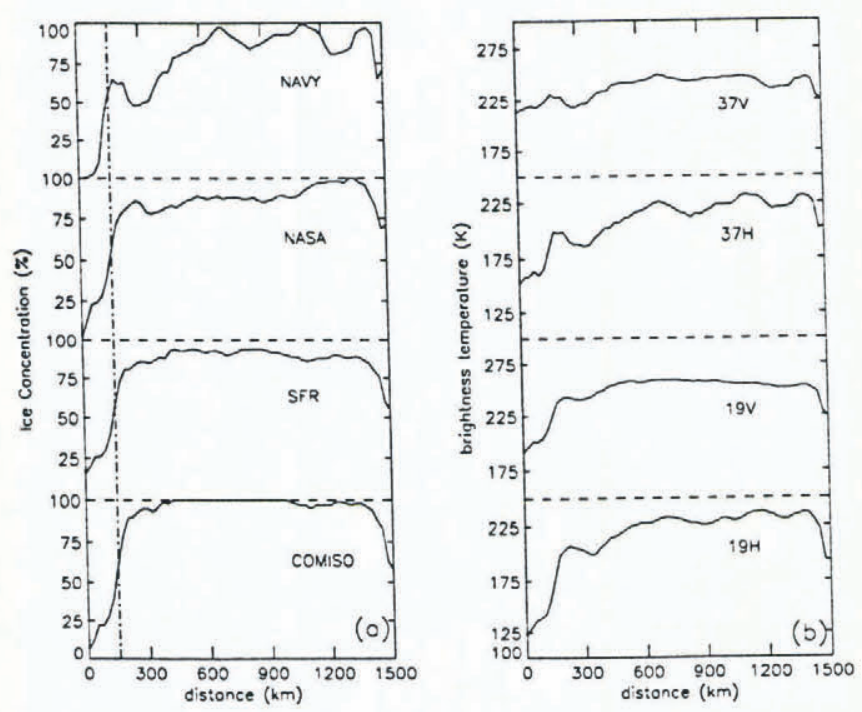

Fig. 2. (a) Ice concentrations along the profile shown in Figure 1 from open ocean (left) across the ice edge to the continent (right). The vertical dashed line indicates the AVHRR ice edge. (b) Brightness temperatures along the same profile. the eastern Weddell Sea, where they agree with COMISO estimates. The maximum discrepancy between these two algorithms is $18 \%$ in the area of the second ice station. The other two algorithms show no such consistent pattern with respect to areas. These trends persist over the week of observations, although the NAVY algorithm exhibits relatively large day-to-day fluctuations. Standard deviations in Table 1 are greatest for areas IS1, ISE and MIZ, all of which are at or fairly close to the ice edge.

Figure 2 shows ice-concentration estimates for single points along a profile from open ocean to the continent. The profile is located in an approximately cloud-free part of the Weddell Sea as indicated by the AVHRR imagery (Fig. 1). Thin clouds are present over the open water but the ice edge is clearly distinguishable. From Figure $2 a$ it is seen that the AVHRR ice edge corresponds to passive microwave ice concentrations of approximately $55 \%$ for all algorithms. Comparison of the ice concentration profiles indicates disagreements of up to $45 \%$ at $300 \mathrm{~km}$ from the ice edge: at this point the estimates are $94 \%$, $86 \%, 84 \%$ and $49 \%$ for the COMISO, SFR, NASA and NAVY algorithms, respectively. The NAVY and NASA profiles also show very different trends from the COMISO and SFR ones. The latter increase from the ice edge to the central Weddell Sea, then decrease again toward the contintent. The former, on the other hand, show a (more-or-less) steady increase from ice edge to continent:

Comparison of the ice-concentration profiles with the brightness temperature profiles in Figure $2 \mathrm{~b}$ indicates that these discrepancies can be attributed to the different algorithms utilizing different frequency/polarization combinations. The strong dependence of the COMISO and SFR algorithms on the $19 \mathrm{~V}$ is clearly seen; this channel also reaches a maximum in the center of this profile. The greater variability and different trend in the NASA algorithm is due to the inclusion of the $19 \mathrm{H}$ channel. Most obvious is the similarity between the $37 \mathrm{H}$ and NAVY ice concentration profiles. That this channel is highly sensitive to snow structure and surface roughness (Grenfell and Lohanick, 1985) suggests that fluctuations 
in the NAVY estimates may not all be due to ice concentration changes.

A comparison for the Weddell Sea as a whole can be made by comparing the passive microwave estimates to those derived from AVHRR. The AVHRR image data were obtained within a few hours of the SSM/I overpasses, which should minimize differences in ice concentration results due to ice motion. The thermal infrared data in channels 3 and 4 are used for cloud detection, and ice concentration is derived from the visible data (channel 1) using a linear model for ice-water mixed pixels based on tie points determined for each image (Burns and others, 1992). Comparison of the AVHRR ice concentration results with analyses of optical image data obtained from a helicopter during WWGS'89 indicate that the AVHRR tends to underestimate the total ice concentration by $5-10 \%$ in areas containing thin ice types.

In order to compare the SSM/I with the AVHRR iceconcentration estimates, the latter are resampled to a $25 \mathrm{~km}$ grid using the SSM/I antenna pattern as a weighting function. Comparisons in the form of scatter plots are shown in Figure 3. Although Figure 1 shows some small cloud-free areas at the ice edge, in this resampling process any areas of $120 \mathrm{~km}$ in diameter which include cloud are eliminated. As Figure 3 shows, the comparison on 30 September therefore only includes ice concentrations greater than about $50 \%$. Within this range, the COMISO estimates are positively biased with respect to those from AVHRR. The SFR estimates are a shifted version of the COMISO estimates because, as mentioned above, these are basically the same algorithm except for the tie points. Higher ice tie points for the SFR algorithm in this case results in a lower bias relative to the AVHRR. The NASA estimates show a somewhat different distribution and a definite negative bias; the root-mean-square differences for the NASA and SFR algorithms are essentially the same and the lowest of the algorithms. The NAVY estimates show the largest scatter and the overall lowest values of the four algorithms examined.

\section{DISCUSSION}

The results presented indicate significant differences between total ice-concentration estimates for the Weddell Sea derived from different algorithms. The question discussed here is whether these differences reflect sensitivities to ice type and/or ice surface conditions not fully or properly accounted for in the algorithms.

As seen in Figure 2, the ice-concentration differences
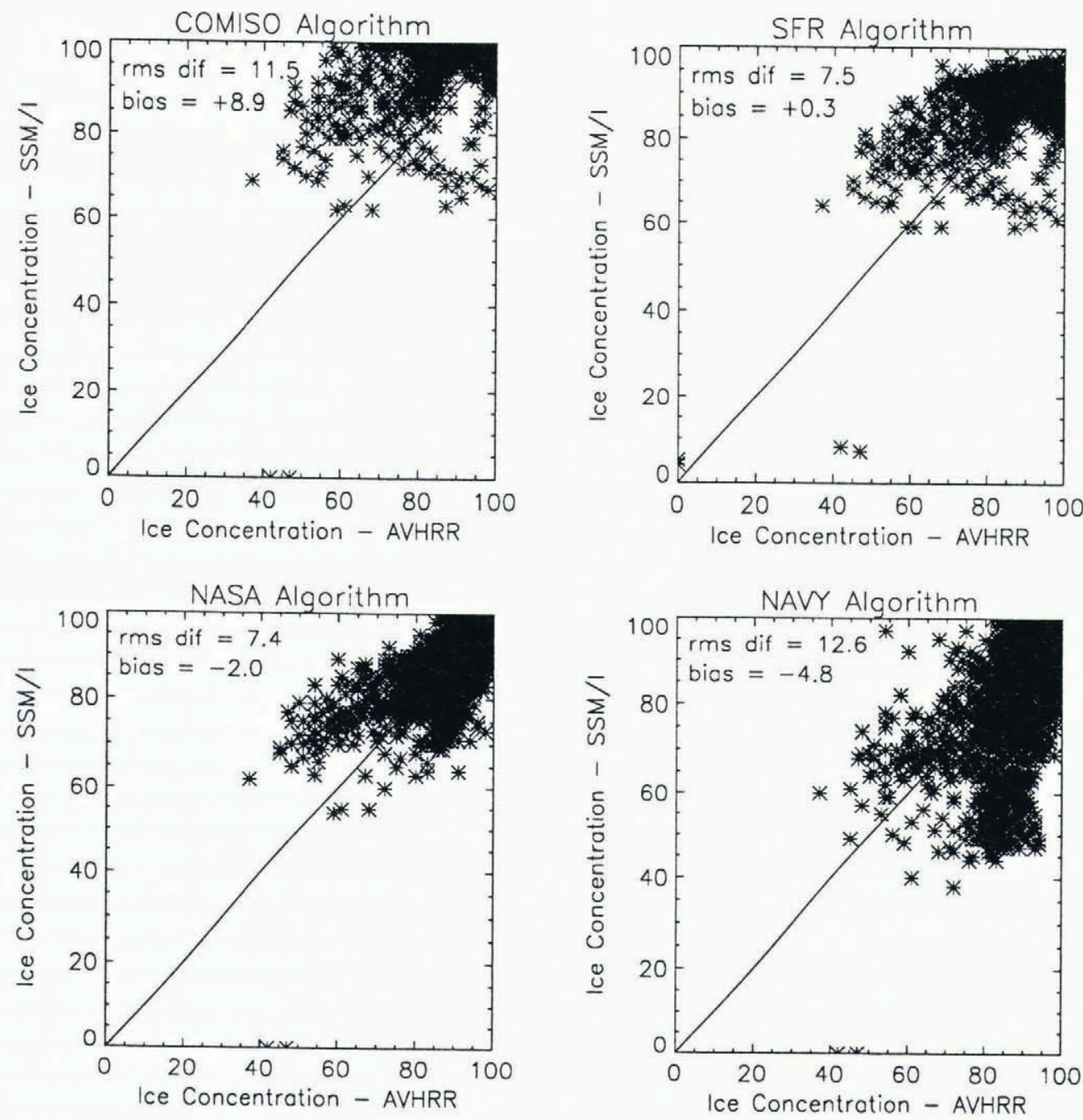

Fig. 3. Comparison of ice concentrations derived from AVHRR visible data with the passive microwave estimates from the four algorithms. Root-mean-square differences and biases relative to the AVHRR estimates are indicated. 

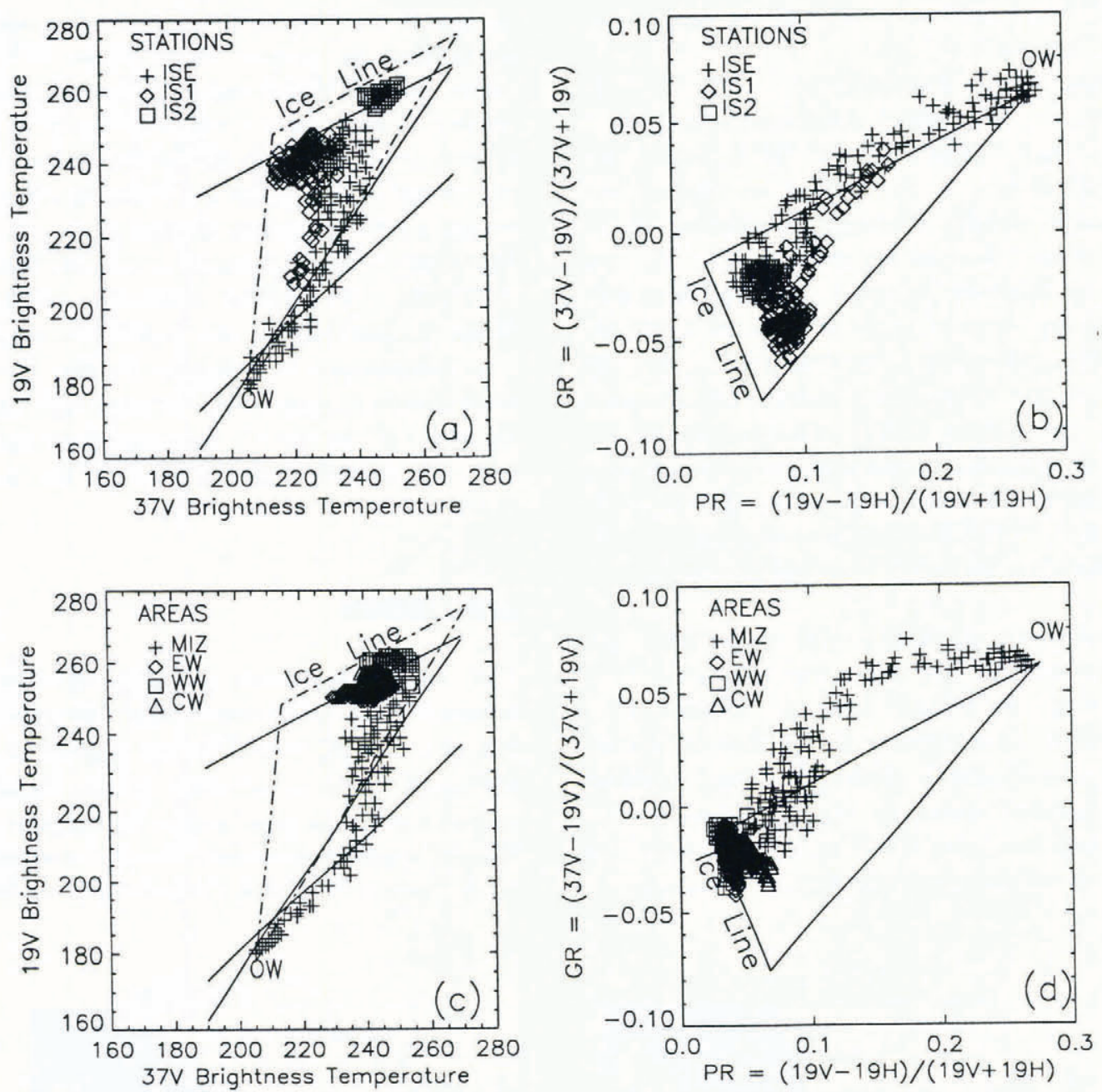

Fig. 4. Scatter plots showing the distribution of sub-area data points in the COMISO, SFR, and NASA algorithm schematics. For definition of sub-areas see Figure 1 and Table 1.

can largely be explained by the behavior of the single data channels, which in turn can be related to the conditions of the ice. For example at $300 \mathrm{~km}$ from the ice edge the brightness temperature profiles show significant dips for the H-polarized relative to the V-polarized channels; almost no dip is seen at $19 \mathrm{~V}$. This difference can be partially explained by the higher sensitivity of the $\mathrm{H}$ polarized channel to small changes in open water amount due to its greater dynamic range. Another possible explanation for these signatures is a larger amount of grease ice or thin ice in this area. Surface measurements presented by Comiso and others (1989) and Grenfell (1986) indicate that the brightness temperatures of grease and $5-10 \mathrm{~cm}$ thick young ice at horizontal polarization $(19$ and $37 \mathrm{GHz}$ ) are greatly reduced, and at vertical only slightly reduced, relative to those of thicker first-year ice. This suggests that algorithms employing the H-polarized channels would underestimate total ice concentration in areas containing very young ice types more than those using V-polarized only. Steffen and Schweiger (1991) found similar results in their validation of the NASA algorithm using Landsat imagery.

This effect is also seen in the scatter plots in Figures $4 \mathrm{a}$ and $b$. The ISI area is located at approximately $400 \mathrm{~km}$ along the profile (Fig. 1). In the scatter plot of brightness temperature at $19 \mathrm{~V}$ versus that at $37 \mathrm{~V}$ (Fig. 4a) the data points in this area cluster near the ice line of the COMISO algorithm, resulting in ice concentration estimates of about $100 \%$. In the plot of GR versus PR (Fig. 4b) illustrating the NASA algorithm, this cluster lies well away from the ice line resulting in lower iceconcentration estimates. This is due to the lower $19 \mathrm{H}$ values and consequent higher PR values for these data points.

The IS2 cluster in these plots shows a similar behavior. The optical image data taken from a helicopter on 30 September indicate ice concentrations of greater than $95 \%$ in this area (personal communication from SchmidtGrottrup). However, observed concentration of white ice was $80-90 \%$, in agreement with the NASA estimates (see Table 1). The COMISO estimates for this area, on the other hand, are $100 \%$ or above. This is also true for the CW and WW areas (Fig. 4c) and for the central part of the profile (Fig. 2a). 19V brightness temperatures in these areas are higher than expected in the COMISO ice model given the $37 \mathrm{~V}$ signatures. Because the model cannot accommodate such signatures, the algorithm fails to produce realistic estimates for these areas. The SFR algorithm is designed specifically to avoid this problem by adjusting the "model" (i.e. tie points) to fit the data (Figures $4 \mathrm{a}$ and $\mathrm{c}$ ).

Figure 4d shows that the IS2 and CW areas also 
behave similarily in the GR-PR plots, suggesting again the possibility that the presence of thin ice affects the total ice concentration estimates of the NASA algorithm. The EW and WW area data both cluster on the ice line such that this algorithm produces realistic estimates. Both areas exhibit similar spreading along this line, contradicting the expectation of different ice type signatures in these two areas. However at this time of year the signature spread may simply be reflecting snow wetness variations and therefore provide no ice type information whatsoever.

Figure 5 presents ice concentration and air temperature time series for area IS2. (These same data were used in the mean values in Table 1). This area was chosen because of its high ice concentration assuring minimal influence from open water and ice dynamics at this location. Also the research vessel Polarstern, from which

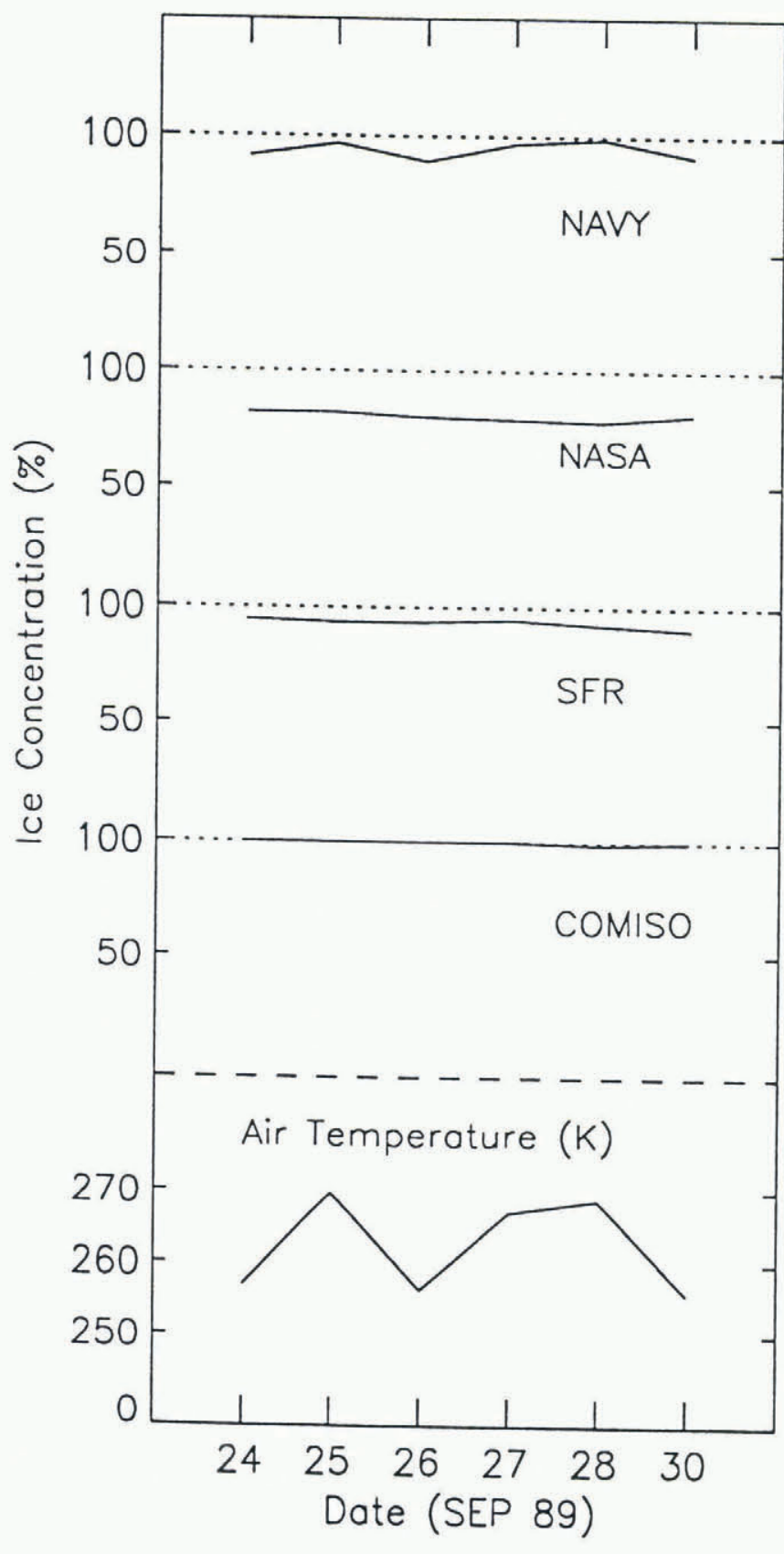

Fig. 5. Time series of air-temperature and ice-concentrations from the four algorithms for sub-area IS2. the air temperature data were taken, was stationary within this area between 27 and 30 September. Comparing the ice-concentration and temperature series, only the NAVY estimates exhibit a clear dependence on air temperature. This could explain some of the relatively high fluctuations in estimates made with this algorithm. It clearly points to the necessity of using brightness temperature ratios, as is done in the other algorithms, to obtain consistent long-term records of ice concentration.

\section{CONGLUSIONS}

Application of four different algorithms to passive microwave imagery of the Weddell Sea produces iceconcentration estimates with discrepancies of up to $45 \%$ when compared on a point-wise basis. Examination of typical sub-areas indicates that the two most widely used algorithms, the COMISO and NASA team, differ by at most $18 \%$ for a single satellite overpass. Some of the observed differences could be explained by the presence of thin ice which causes algorithms utilizing the H-polarized channels to underestimate total ice concentration. This is supported by observations with coincident high-resolution optical data obtained from a helicopter: concentrations of white ice derived from these data agree well with the NASA total ice concentration estimates. Such sensitivity to lower albedo ice types is clearly important for climate modeling, but the algorithm must incorporate information additional to the spectral gradient ratio in order to distinguish ice type from ice concentration variations.

Algorithms using only V-polarized data do not show this sensitivity to the thin ice but they presently lack an adequate model to account for other variations in the $19 \mathrm{~V}$ data that are not apparently related to ice-concentration changes. In the COMISO algorithm, which uses fixed tie points, this can lead to unrealistically high estimates. Use of tie points derived from the data, as is done in the SFR algorithm, improves the results. Indeed the NASA algorithm also showed improved performance with the use of seasonally and regionally adjusted tie points (Steffen and Schweiger, 1991).

It has also been demonstrated that algorithms not employing ratios of data channels or tie points derived from the data are subject to errors from air-temperature fluctuations. The results presented here have been derived for a limited set of environmental conditions, namely Antarctic spring. Algorithm sensitivities need to be compared for other seasons when significantly colder or warmer air temperatures influence both ice-surface conditions and the partial concentrations of young-ice types.

\section{REFERENCES}

Burns, B. A., M. Schmidt-Grottrup and T. Viehoff. 1992. Methods for digital analysis of AVHRR sea ice images. IEEE Trans. Geosci. Remote Sensing, 30(3), 589-602.

Cavalieri, D.J., P. Gloersen and W.J. Campbell. 1984. Determination of sea ice parameters with the NIM- 
BUS 7 SMMR. 7. Geophys. Res., 89(D4), 5355-5369.

Comiso, J. C. and C. W. Sullivan. 1986. Satellite microwave and in situ observations of the Weddell Sea ice cover and its marginal ice zone. F. Geophys. Res., 91(C8), 9663-9681.

Comiso, J. C., T. C. Grenfell, D. L. Bell, M. A. Lange and S. F. Ackley. 1989. Passive microwave in situ observations of winter Weddell Sea ice. 7. Geophys. Res., 94(C8), 10,891-10,905.

Gloersen, P. and D.J. Cavalieri. 1986. Reduction of weather effects in the calculation of sea ice concentration from microwave radiances. F. Geophys. Res., 91(C3), 3913-3919.

Grenfell, T. C. 1986. Surface-based passive microwave observations of sea ice in the Bering and Greenland seas. IEEE Trans. Geosci. Remote Sensing, GE-24(3), 378382.

Grenfell, T.C. and A.W. Lohanick. 1985. Temporal variations of the microwave signatures of sea ice during the late spring and early summer near Mould Bay, NWT. 7. Geophys. Res., 90(C3), 5063-5074.

Hollinger, J., coord. 1989. DMSP Specal Sensor Microwave Imager calibration/validation: final report. Washington, DC, Naval Research Laboratory.

Steffen, K. and A. Schweiger. 1991. NASA Team algorithm for sea ice concentration retrieval from Defense Meteorological Satellite Program Special Sensor Microwave Imager: comparison with Landsat satellite imagery. F. Geophys. Res., 96(C12), 21,971$21,987$.

Swift, C. T., L. S. Fedor and R. O. Ramseier. 1985. An algorithm to measure sea ice concentration with microwave radiometers. F. Geophys. Res., $90(\mathrm{C1})$, 1087-1099.

The accuracy of references in the text and in this list is the responsibility of the author, to whom queries should be addressed. 